\title{
Different Treatments for Granulomatous Lobular Mastitis: A Systematic Review and Meta-Analysis
}

\author{
Xiaojia Ma ${ }^{a}$ b Xiaoli Min ${ }^{c}$ Chang Yao ${ }^{d}$ \\ ${ }^{a}$ Nanjing University of Chinese Medicine, Nanjing, China; ${ }^{b}$ Yunnan Provincial Hospital of Traditional Chinese \\ Medicine, Kunming, China; ${ }^{C}$ Department of Cerebrovascular Diseases, the Second Affiliated Hospital of \\ Kunming Medical University, Kunming, China; ${ }^{\mathrm{d}}$ The First Affiliated Hospital of Nanjing University of Chinese \\ Medicine, Nanjing, China
}

\section{Keywords}

Granulomatous lobular mastitis · Meta-analysis · Steroids . Surgical excision

\begin{abstract}
Objective: Granulomatous lobular mastitis (GLM) is infrequently diagnosed. This study aimed to evaluate the efficacy and safety of managements for GLM in the nonlactation period. Methods: Publications were retrieved from PubMed, EMBASE, and the Cochrane library on September 10, 2018. We pooled and compared the outcome parameters and complete remission (CR) rates between different treatments using a meta-analysis. Results: Twenty-one publications including 970 patients treated with surgical excision, steroids, abscess drainage, antibiotics, and observation were included. Surgery significantly improved $C R$ rate compared with steroids $(p=0.0003)$. There was no difference in the $C R$ rate in patients treated with surgery alone or combined with steroids ( $p=0.28)$. Surgery showed borderline significant efficacy in the $\mathrm{CR}$ rate compared with antibiotics $(p=0.06)$ and abscess drainage $(p=0.06)$. No difference was observed in effectiveness between observation and surgical management in patients diagnosed with early GLM and mild symptoms. Conclusions: Although surgery was the ideal management for GLM, steroids and antibiotics might be ideal managements for GLM patients who are worried about surgical scars. Observation was an impressive alternative for patients with early GLM.

๑) 2019 S. Karger AG, Basel
\end{abstract}

\section{Introduction}

Granulomatous lobular mastitis (GLM), also known as idiopathic granulomatous mastitis or idiopathic GLM, is a rare chronic inflammatory pseudotumor of the breast and is a typical nonpuerperal mastitis. GLM is characterized by noncaseating chronic granulomatous inflammation and breast lobules $[1,2]$. The causes of GLM are various, including a history of pregnancy, breast-feeding, autoimmunity, infection, tuberculosis, hormonal imbalance, oral contraceptives, $\alpha 1$-antitrypsin deficiency, smoking, and sarcoidosis [3-5]. However, the occurrence of GLM is reported more often nowadays, and the etiology of GLM has not been fully elucidated till now.

The usual treatments for GLM are surgical excision, abscess drainage, and use of corticosteroids, antibiotics, methotrexate (MTX), and anti-inflammatory medications [1, 6-8]. The usage of steroids could achieve an over $70 \%$ recovery rate $[6,9]$. Close observation also achieved a good recovery rate in selected patients with early GLM, mild symptoms, or women who intend to become pregnant [10-12]. A meta-analysis study reported that the complete remission (CR) rate of idiopathic granulomatous mastitis treated with surgery, oral steroids plus surgery, and oral steroids single therapy was 90.6, 94.5, and $71.8 \%$, respectively [13]. However, there is no clinical consensus on the ideal therapeutic and universally accepted management strategy for GLM. 
Table 1. Baseline characteristics of the 21 eligible studies included in this review

\begin{tabular}{|c|c|c|c|c|c|}
\hline First author [ref.], year & $\begin{array}{l}\text { Patients, } \\
n\end{array}$ & Age, years ${ }^{a}$ & Methodology & Follow-up period ${ }^{\mathrm{a}}$ & $\begin{array}{l}\text { Jadad } \\
\text { score }\end{array}$ \\
\hline Li [8], 2018 & 75 & $35.84 \pm 9.98(21-61)$ & surgery/steroids/antibiotics & $12(1-60)^{\mathrm{c}}$ & 5 \\
\hline Shin [3], 2017 & 34 & $37(24-47)$ & $\begin{array}{l}\text { surgery/steroids/antibiotics/ } \\
\text { observation }\end{array}$ & $45.5(22-98)^{\mathrm{c}}$ & 4 \\
\hline Akahane [15], 2013 & 12 & $36(25-47)$ & surgery/steroids & $22(6-104)^{c}$ & 5 \\
\hline Hovanessian Larsen [10], 2009 & 54 & $33.1(22-44)$ & $\begin{array}{l}\text { surgery/steroids/antibiotics/ } \\
\text { observation }\end{array}$ & $\mathrm{NA}\left(3-27^{\mathrm{C}}\right)$ & 5 \\
\hline Gurleyik [4], 2012 & 19 & $34.1(27-59)$ & surgery/steroids & $20(6-75)^{\mathrm{c}}$ & 3 \\
\hline Néel [17], 2013 & 23 & $39(25-61)$ & surgery/steroids/antibiotics & $75^{c}\left(14^{c}-28^{b}\right)$ & 4 \\
\hline Akcan [18], 2014 & 74 & $34.8 \pm 11.7$ & surgery/steroids & $41(3-170)^{\mathrm{c}}$ & 5 \\
\hline Gunduz [1], 2014 & 11 & $35(24-46)$ & steroids & $17(12-48)^{\mathrm{c}}$ & 4 \\
\hline Karanlik [19], 2014 & 37 & $34(23-57)$ & surgery/steroids/observation & $38(22-78)^{\mathrm{c}}$ & 5 \\
\hline Kiyak [20], 2014 & 24 & $38.4(28-60)$ & surgery & $34.8(10-66)^{\mathrm{c}}$ & 5 \\
\hline Pandey [6], 2014 & 49 & $35(24-67)$ & surgery/steroids/observation & NA $\left(6-12^{c}\right)$ & 4 \\
\hline Aghajanzadeh [9], 2015 & 206 & $32(22-40)$ & surgery/steroids/antibiotics & $\mathrm{NA}\left(9-18^{\mathrm{c}}\right)$ & 4 \\
\hline Altintoprak [16], 2015 & 52 & $35.7(24-48)$ & surgery/steroids/antibiotics & $37.2(12-72)^{\mathrm{c}}$ & 4 \\
\hline Bouton [21], 2015 & 37 & $33(22-46)$ & surgery/antibiotics/observation & $7.4(0-20)^{\mathrm{c}}$ & 5 \\
\hline Mahlab-Guri [12], 2015 & 17 & $44.6 \pm 12.6(30-72)$ & antibiotics/observation & $4.7 \pm 3.8(0.5-13)^{\mathrm{b}}$ & 3 \\
\hline Sheybani [7], 2015 & 22 & $32.8 \pm 6.2(23-47)$ & steroid/MTX & $11.96 \pm 4.4(6-22)^{c}$ & 4 \\
\hline Yabanoğlu [22], 2015 & 77 & $36(28-68)$ & surgery/steroids & $18(1-120)^{\mathrm{c}}$ & 5 \\
\hline Sakurai [23], 2011 & 8 & $44.8(28-75)$ & surgery/steroids/antibiotics & $40.3(14-67)^{c}$ & 2 \\
\hline Hur [11], 2013 & 50 & $37.1 \pm 7.9$ & surgery/steroids/antibiotics & $\mathrm{NA}\left(32.0 \pm 18.1^{\mathrm{c}}\right)$ & 3 \\
\hline Kok and Telisinghe [24], 2010 & 43 & 34 & surgery/steroids & $15(1-80)^{\mathrm{c}}$ & 2 \\
\hline Oran [25], $2013^{\circ}$ & 46 & $33(28-55)$ & surgery/steroids & $35.4(3-135)^{\mathrm{c}}$ & 4 \\
\hline
\end{tabular}

NA, not available. ${ }^{a}$ Age and follow-up period were presented as median (range) or average (mean $\pm \mathrm{SD}$ ) and/or range in parentheses in different studies. ${ }^{\mathrm{b}}$ Years. ${ }^{\mathrm{c}}$ Months.

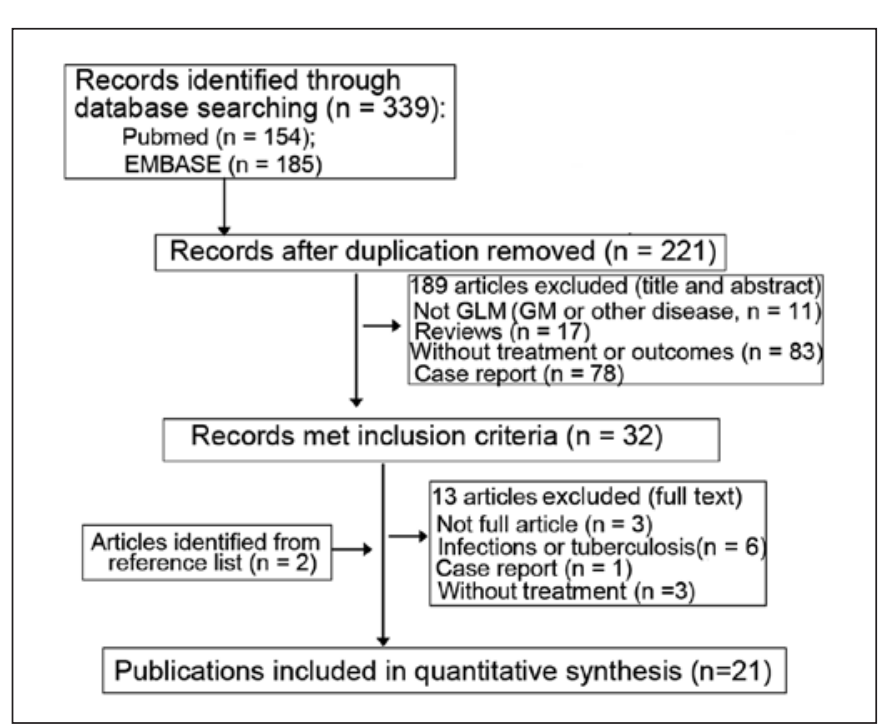

Fig. 1. Adapted PRISMA flow diagram. GLM, granulomatous lobular mastitis; GM, granulomatous mastitis.

We performed this meta-analysis by a pooled analysis of the data from publications to compare the CR rate of different treatments for GLM in the nonlactation period. A total of 21 publications were included in this study. The CR rates of surgery, steroids, surgery plus steroids, anti- biotics, observation, and MTX management of GLM were compared to evaluate the effectiveness of different treatments for GLM.

\section{Methods}

Search Strategy

We conducted this review following the PRISMA (Preferred Reporting Items for Systematic Reviews and Meta-Analyses) guidelines [14]. Two reviewers (X.M. and C.Y.) conducted the systematic search of papers published in English language in databases, including PubMed, EMBASE, and Cochrane library, using the search terms "nonpuerperal mastitis," "periductal mastitis," "granulomatous lobular mastitis," "mastitis," "surgical," or "steroids." Additional studies were identified from references, and studies lacking sufficient data were excluded. Publications from the earliest record of the databases to September 10, 2018, were selected.

\section{Inclusion and Exclusion Criteria}

Studies were included if they met the following criteria: (1) including patients with nonpuerperal mastitis/periductal mastitis; (2) designed as randomized controlled trials, case-control studies, or cohort study with or without controls; (3) using different treatment strategies; and (4) outcomes and curative effect reported. Publications were excluded if they met the following criteria: (1) including patients with communicable diseases and other breast diseases; (2) reports on granulomatous mastitis; (3) reports without outcomes of patients; (4) observations without controls; (5) 


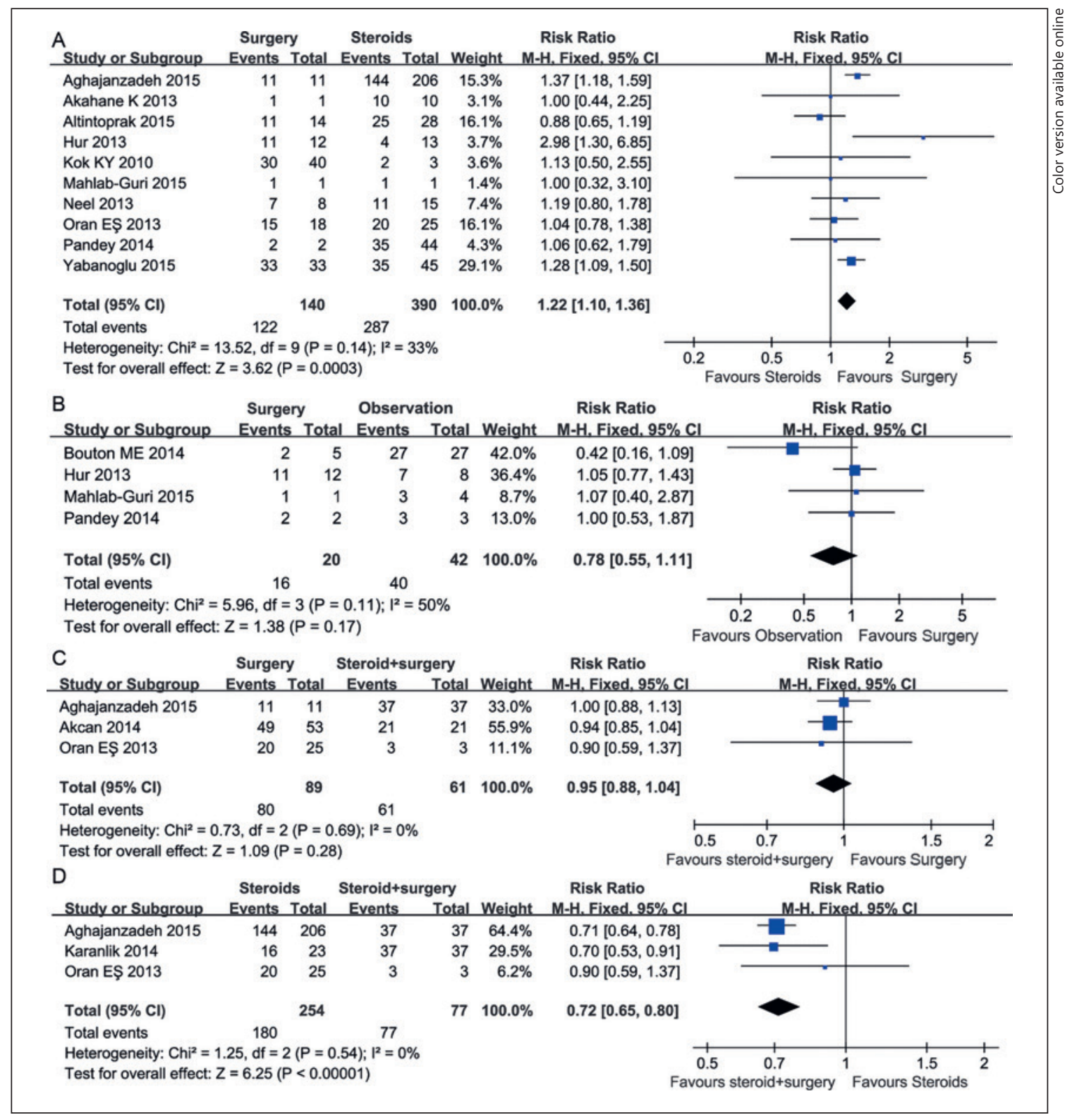

Fig. 2. Forest plot for the clinical effectiveness of surgical management for GLM patients. A Pooled analysis of 10 studies including surgery and steroid treatment. B Pooled analysis of 4 studies covering patients diagnosed with early GLM and treated with close observation or surgical excision. C Pooled analysis of 3 studies including comparative outcomes of GLM patients treated with surgery and surgery plus steroids. D Pooled analysis of 3 studies including GLM patients treated with steroids and steroids plus surgery. GLM, granulomatous lobular mastitis; M-H, Mantel-Haenszel.

clinical trials without statistical analyses; and (6) case reports without treatment description and documented outcome.

\section{Endpoints}

The primary outcome measures included (1) CR, described as breast fistula healed and lumps disappeared; (2) improved, described as breast fistula almost healed, lumps reduced, and swelling and pain disappeared; (3) no effect, defined as persistent fistula and lumps not reduced.

Quality Extraction and Evaluation

Two reviewers (J.M. and C.Y.) conducted data extraction independently. Publication quality and risk of bias was evaluated using the 5-point Jadad scoring tool. Studies with scores of $\geq 3$ were considered as high-quality publications. The evidence strength was evaluated using GradePro ${ }^{\circledR}$ (Cochrane Collaboration, https:// www.cochranelibrary.com/). Egger's linear regression test was used to assess publication bias.

\section{Statistical Analysis and Meta-Analysis}

Revman 5.0 software was used for the meta-analysis (with 95\% confidence interval [CI]). Heterogeneity across the included studies was analyzed using the $\chi^{2}$ test and was evaluated using the $I^{2}$ test. If $I^{2} \geq 50 \%$, studies were considered to have significant heterogeneity, and a random-effects model was used for the analysis of parameters; otherwise, parameters in studies were analyzed using 


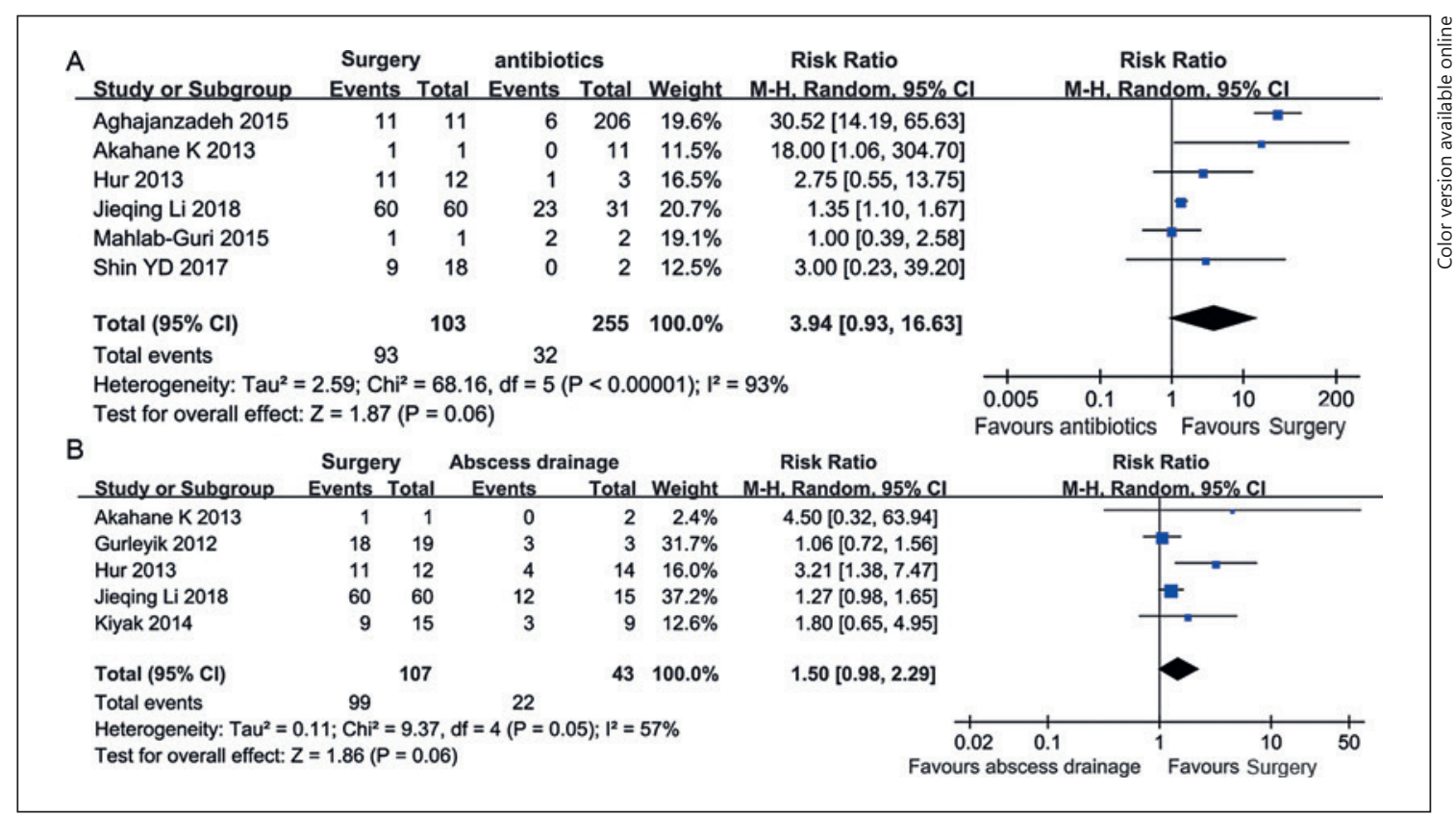

Fig. 3. Forest plot for the clinical effectiveness of surgical management for GLM patients compared with antibiotics (A) and abscess drainage (B). GLM, granulomatous lobular mastitis; M-H, Mantel-Haenszel.

a fixed-effects model $\left(I^{2}<50 \%\right)$. Sensitivity was analyzed if the source of heterogeneity was derived from low quality. Risk ratios (RR) or mean differences together with 95\% CI were reported for dichotomous data using the Mantel-Haenszel (M-H) method.

\section{Study Selection}

The flow diagram is shown in Figure 1. A total of 339 articles were searched entering the search terms, and 21 publications were finally included in this study based on the inclusion and exclusion criteria. The detailed characteristics of these 21 publications are shown in Table 1. All publications were case-control studies. No significant publication bias was found.

\section{Study Characteristics}

A total of 970 patients with GLM treated with surgical excision, abscess drainage, steroids as single therapy or in combination prior to or after surgery, antibiotics, and observation were included in these studies. Patients were assigned to different treatments, including surgical management $(n=265)$ [3, 4, 6, 8-11, 15-25], steroids only $(n=390)[1,7,11,22,24,25]$, steroids plus MTX $(n=$ $68)[7,9,12]$, steroids plus surgery or in reverse order $(n=98)[9$, $18,19,25]$, bromocriptine $(n=16)$ [9], antibiotics (dicloxacillin, cephalexin, or clindamycin, $n=256)[3,8-12,16,17,21,23]$, abscess drainage $(n=18)[11,12]$, and observation only [3, 6, 10-12, $19,21]$. All patients received steroids (oral or topical) in various dosages.

\section{Results}

\section{Surgery Significantly Improves CR of GLM in}

Comparison with Steroids, Antibiotics, and Drainage

Pooled data analysis showed that surgery significantly improved the rate of $\mathrm{CR}$ compared with steroids $(\mathrm{RR}=$
1.22, 95\% CI [1.10, 1.36], $p=0.0003, I^{2}=33 \%$; Fig. 2A). In patients diagnosed as early GLM with mild symptoms, close observation obtained impressive effectiveness in terms of CR compared with surgery, with no statistically significant difference $(\mathrm{RR}=0.78,95 \% \mathrm{CI}[0.55,1.11], p=$ $0.17, I^{2}=50 \%$; Fig. 2B).

Pooled analysis showed that there was no difference in the CR rate of GLM between surgery-treated patients with or without steroids $(\mathrm{RR}=0.95,95 \% \mathrm{CI}[0.88,1.04]$, $I^{2}=0 \%, p=0.28$; Fig. $\left.2 \mathrm{C}\right)$. However, additional surgical excision significantly improved the recovery rate compared with steroids single therapy $(\mathrm{RR}=0.72,95 \% \mathrm{CI}$ $[0.65,0.80], I^{2}=0 \%, p<0.00001$; Fig. 2D). Moreover, we found that surgery achieved borderline significant effectiveness in CR rates compared with antibiotics $(\mathrm{RR}=$ $3.94,95 \%$ CI $[0.93,16.63], I^{2}=93 \%, p=0.06$; Fig. $\left.3 \mathrm{~A}\right)$ and abscess drainage $\left(\mathrm{RR}=1.50,95 \% \mathrm{CI}[0.98,2.29], I^{2}=57 \%\right.$, $p=0.06$; Fig. 3B).

\section{Steroids Treatment Showed Better Effectiveness for}

GLM Remission than Abscess Drainage, Antibiotics, and MTX

Meta-analysis showed that steroids single therapy achieved borderline significant effectiveness for the GLM $\mathrm{CR}$ rate compared with antibiotics $(\mathrm{RR}=5.67,95 \% \mathrm{CI}$ [0.87, 37.06], $p=0.07, I^{2}=91 \%$; Fig. $4 \mathrm{~A}$ ); observation showed significant improvement in CR rates in patients with early GLM and mild symptoms compared with steroids $\left(\mathrm{RR}=0.69,95 \% \mathrm{CI}[0.51,0.95], I^{2}=46 \%, p=0.02\right.$; Fig. 4B) and showed equivalent effectiveness to abscess 


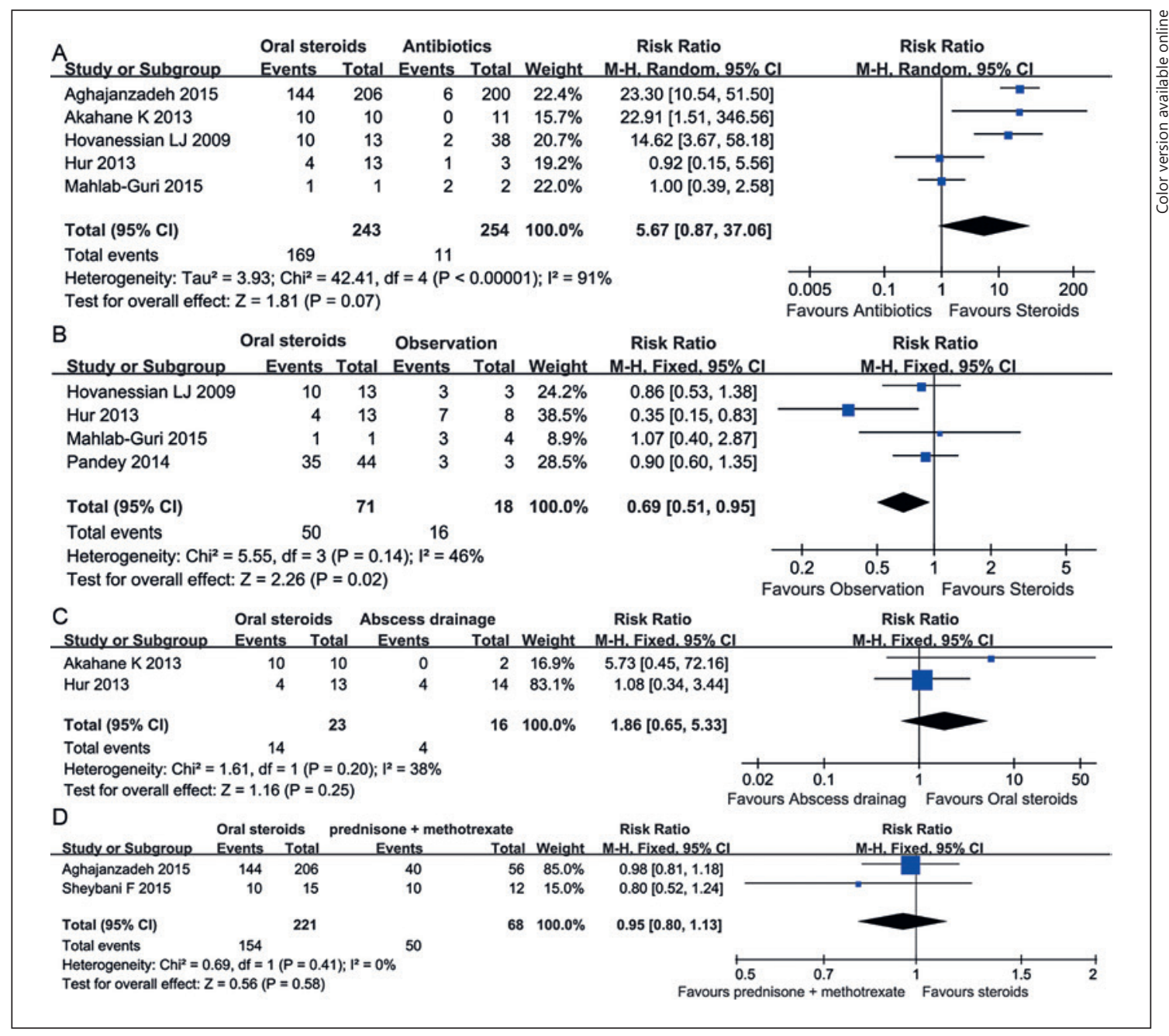

Fig. 4. Forest plot for the clinical effectiveness of steroids management for GLM patients. A Pooled analysis of 5 studies including GLM patients treated with steroids and antibiotics. B Pooled analysis of 4 studies covering patients diagnosed with early GLM and treated with steroids or close observation. C Pooled analysis of 2 studies including comparative outcomes of GLM patients treated with steroids and abscess drainage. D Pooled analysis of 2 studies including GLM patients treated with steroids and prednisone plus methotrexate. GLM, granulomatous lobular mastitis; M-H, Mantel-Haenszel.

drainage $\left(\mathrm{RR}=1.86,95 \%\right.$ CI $[0.65,5.33], I^{2}=38 \%, p=$ 0.25 , M-H methods, fixed model; Fig. 4C) and prednisone plus MTX $\left(\mathrm{RR}=0.95,95 \%\right.$ CI $[0.80,1.13], I^{2}=0 \%, p=$ 0.58; Fig. 4D).

\section{Effectiveness of Observation for Patients with Early \\ GLM}

Figure 5 shows that the effectiveness of observation for the CR rate of GLM was significantly higher than that of abscess drainage treatment $(\mathrm{RR}=3.06,95 \%$ CI $[1.28$, 7.30], $p=0.01$; Fig. $5 \mathrm{~A}$ ), and it was equivalent with antibiotics $\left(\mathrm{RR}=1.27,95 \% \mathrm{CI}[0.34,4.71], I^{2}=57 \%, p=0.72\right.$; Fig. 5B). These results suggest that observation is an impressive alternative for patients diagnosed with early GLM and mild symptoms.

\section{Discussion}

The meta-analysis of 21 publications included in this study enrolled 970 GLM patients who were treated with surgical excision, oral or topical steroids, steroids plus surgery, abscess drainage, antibiotics management, MTX, and observation. Meta-analysis showed that surgical management was the best choice for GLM CR, followed by steroids combined with surgical management and steroids single therapy. We also found that GLM patients treated with steroids plus surgical management showed a significantly increased CR rate compared with steroids alone. There were no differences in CR rates between patients treated with steroids and those treated with antibiotics, abscess drainage, and prednisone plus MTX. These 


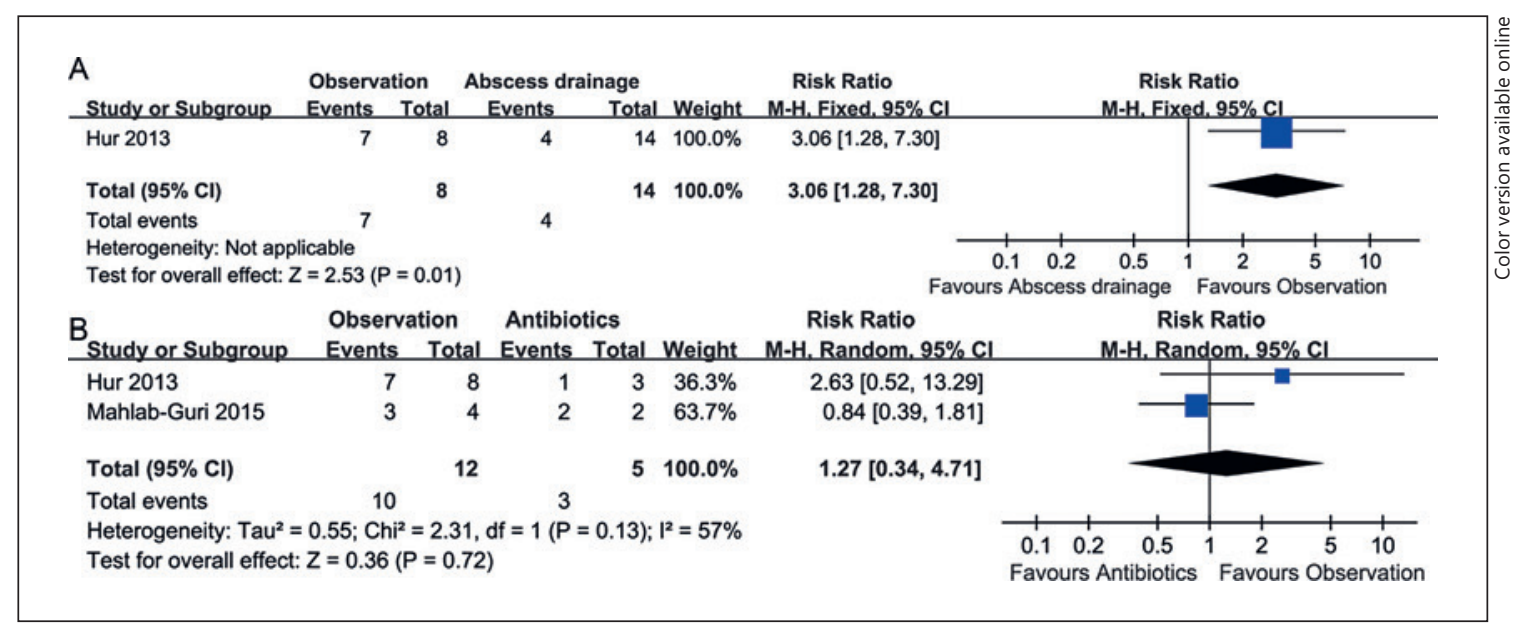

Fig. 5. Forest plot for the effectiveness of observation for GLM patients. A Pooled analysis of 5 studies including GLM patients treated with observation and abscess drainage. B Pooled analysis of 2 studies covering patients diagnosed with GLM and treated with antibiotics or close observation. GLM, granulomatous lobular mastitis; M-H, Mantel-Haenszel.

results suggest the effectiveness of surgical and steroids management for GLM.

The best and fastest way to complete eradication of GLM was surgical management. Surgical management, with or without steroids, achieved high CR rates with low recurrence rates [9, 13, 22, 24]. Yabanoğlu et al. [22] treated 31 GLM patients with surgical excision and 44 GLM patients with steroids and found that the recurrence rate of surgical management was $0 \%$ during the follow-up period (1-120 months), which was significantly lower than $6.2 \%$ (9/44) with management by steroids. Lei et al. [13] performed a meta-analysis, which included publications of our study, and found that GLM patients treated with surgical excisions had a higher CR rate (90.6\%) than those with oral steroids single therapy (71.8\%). In addition, they also reported that the addition of steroids to surgery increased the CR rate $(94.5 \%)$ and decreased the recurrence rate (4.0\%) of GLM compared with surgical management alone (6.8\% recurrence rate). Akcan et al. [18] also reported that the administration of steroids prior to surgery decreased the GLM recurrence rate $(0 \%$ in the steroids plus surgery group vs. $7.5 \%$ in the surgery group). In addition to the high $\mathrm{CR}$ rate and low recurrence rate, surgical excision might provide a shorter reconvalescence [22]. Our metaanalysis showed that surgery obviously achieved higher CR rates in GLM patients than steroids. Accordingly, surgery sounds like the best way to treat GLM. But the problem of scarring has to be considered in decision-making.

GLM is identified as a self-limiting condition in certain cases and can disappear on its own with close observation $[26,27]$. Accordingly, close surveillance or observation is an acceptable nonsurgical management for GLM diagnosed at an early period with mild symptoms or for patients tending to conservative treatments. Five includ- ed studies $[6,10-12,21]$ reported that $95.55 \%(43 / 45)$ of GLM patients diagnosed at an early period or with mild symptoms showed spontaneous resolution. However, close observation needs patient education and patience due to a long course (10-22 months) $[12,21]$ and is always accompanied by high recurrence rates $[11,21]$.

The most effective acceptable nonsurgical management for GLM is oral or topical application of corticosteroids. They are used to treat GLM due to their anti-inflammatory and immunosuppressive effects [28]. The improvement rate of steroid treatment is approximately $70-80 \%[6,9,10,13]$.

The etiology of GLM has not been fully elucidated. GLM is commonly characterized by chronic mammary inflammation, giant cell formation, background neutrophils, and necrosis in the breast $[29,30]$. Both MTX and steroids are immunosuppressive agents used for GLM management [31, 32]. Bouton et al. [33] reported that the management strategy with bromocriptine, a prolactin-lowering drug, was effective for GLM, suggesting the complex pathogenesis of GLM. GLM is reported to be associated with Corynebacteria infection $[34,35]$. Accordingly, the administration of antibiotics showed an impressive effect on the CR rate of GLM. Our study showed that steroids and antibiotics had equivalent effectiveness for GLM. This was also true for steroids in comparison to prednisone plus MTX. These results suggested that antibiotics and MTX plus steroids might be the initial option for GLM conservative treatment as an alternative to steroids.

There were 2 limitations in our meta-analysis: (1) a nonstandardized definition of CR of GLM and (2) the subjective choice of patients or physicians for nonsurgical management. These issues limit the statement of our study and our final conclusion. 


\section{Conclusion}

Based on the findings of our current study derived from the meta-analysis of case-control studies, one may conclude that surgical management should be the firstline treatment for GLM. For patients refusing surgical scarring, steroids and antibiotics should be the initial treatment strategy. Observation might be the primary treatment for GLM patients with early GLM and mild symptoms and for patients who are worried about scars.

\section{Statement of Ethics}

This article does not contain any studies with human participants performed by any of the authors.

\section{Disclosure Statement}

The authors have no conflicts of interest to declare.

\section{Funding Sources}

There were no funding sources.

\section{References}

1 Gunduz Y, Altintoprak F, Tatli Ayhan L, Kivilcim T, Celebi F. Effect of topical steroid treatment on idiopathic granulomatous mastitis: clinical and radiologic evaluation. Breast J. 2014 Nov-Dec;20(6):586-91.

2 Jeon JJ, Lee K, Kim Y, Yong SC, Park HK. Retrospective Analysis of Idiopathic Granulomatous Mastitis: Its Diagnosis and Treatment. J Breast Dis. 2017 Dec;5(2):82-8.

3 Shin YD, Park SS, Song YJ, Son SM, Choi YJ. Is surgical excision necessary for the treatment of Granulomatous lobular mastitis? BMC Womens Health. 2017 Jul;17(1):49.

4 Gurleyik G, Aktekin A, Aker F, Karagulle H, Saglamc A. Medical and surgical treatment of idiopathic granulomatous lobular mastitis: a benign inflammatory disease mimicking invasive carcinoma. J Breast Cancer. 2012 Mar; 15(1):119-23.

5 Uysal E, Soran A, Sezgin E; Granulomatous Mastitis Study Group. Factors related to recurrence of idiopathic granulomatous mastitis: what do we learn from a multicentre study? ANZ J Surg. 2018 Jun;88(6):635-9.

6 Pandey TS, Mackinnon JC, Bressler L, Millar A, Marcus EE, Ganschow PS. Idiopathic granulomatous mastitis-a prospective study of 49 women and treatment outcomes with steroid therapy. Breast J. 2014 May-Jun;20(3):258-66.

7 Sheybani F, Sarvghad M, Naderi HR, Gharib M. Treatment for and clinical characteristics of granulomatous mastitis. Obstet Gynecol. 2015 Apr;125(4):801-7.

8 Li J. Diagnosis and Treatment of 75 Patients with Idiopathic Lobular Granulomatous Mastitis. J Invest Surg. 2018 Jan:1-7.

9 Aghajanzadeh M, Hassanzadeh R, Alizadeh Sefat S, Alavi A, Hemmati H, Esmaeili Delshad MS, et al. Granulomatous mastitis: Presentations, diagnosis, treatment and outcome in 206 patients from the north of Iran. Breast. 2015 Aug;24(4):456-60.

10 Hovanessian Larsen LJ, Peyvandi B, Klipfel N, Grant E, Iyengar G. Granulomatous lobular mastitis: imaging, diagnosis, and treatment. AJR Am J Roentgenol. 2009 Aug;193(2):57481.

11 Hur SM, Cho DH, Lee SK, Choi MY, Bae SY, Koo MY, et al. Experience of treatment of patients with granulomatous lobular mastitis. J Korean Surg Soc. 2013 Jul;85(1):1-6.

12 Mahlab-Guri K, Asher I, Allweis T, Diment J, Sthoeger ZM, Mavor E. Granulomatous Lobu- lar Mastitis. Isr Med Assoc J. 2015 Aug;17(8): 476-80.

13 Lei X, Chen K, Zhu L, Song E, Su F, Li S. Treatments for Idiopathic Granulomatous Mastitis: Systematic Review and Meta-Analysis. Breastfeed Med. 2017 Sep;12(7):415-21.

14 Moher D, Liberati A, Tetzlaff J, Altman DG; PRISMA Group. Preferred reporting items for systematic reviews and meta-analyses: the PRISMA statement. Ann Intern Med. 2009 Jul; 151(4):264-9.

15 Akahane K, Tsunoda N, Kato M, Noda S, Shimoyama Y, Ishigakis S, et al. Therapeutic strategy for granulomatous lobular mastitis: a clinicopathological study of 12 patients. Nagoya J Med Sci. 2013 Aug;75(3-4):193-200.

16 Altintoprak F, Kivilcim T, Yalkin O, Uzunoglu Y, Kahyaoglu Z, Dilek ON. Topical Steroids Are Effective in the Treatment of Idiopathic Granulomatous Mastitis. World J Surg. 2015 Nov;39(11):2718-23.

17 Néel A, Hello M, Cottereau A, Graveleau J, De Faucal P, Costedoat-Chalumeau N, et al. Longterm outcome in idiopathic granulomatous mastitis: a western multicentre study. QJM. 2013 May; 106(5):433-41.

18 Akcan A, Öz AB, Dogan S, Akgün H, Akyüz M, Ok E, et al. Idiopathic Granulomatous Mastitis: Comparison of Wide Local Excision with or without Corticosteroid Therapy. Breast Care (Basel). 2014 May;9(2):111-5.

19 Karanlik H, Ozgur I, Simsek S, Fathalizadeh A, Tukenmez M, Sahin D, et al. Can Steroids plus Surgery Become a First-Line Treatment of Idiopathic Granulomatous Mastitis? Breast Care (Basel). 2014 Oct;9(5):338-42.

20 Kiyak G, Dumlu EG, Kilinc I, Tokaç M, Akbaba S, Gurer A, et al. Management of idiopathic granulomatous mastitis: dilemmas in diagnosis and treatment. BMC Surg. 2014 Sep; 14(1):66.

21 Bouton ME, Jayaram L, O’Neill PJ, Hsu CH, Komenaka IK. Management of idiopathic granulomatous mastitis with observation. Am J Surg. 2015 Aug;210(2):258-62.

22 Yabanoğlu H, Çolakoğlu T, Belli S, Aytac HO, Bolat FA, Pourbagher A, et al. A Comparative Study of Conservative versus Surgical Treatment Protocols for 77 Patients with Idiopathic Granulomatous Mastitis. Breast J. 2015 JulAug;21(4):363-9.

23 Sakurai K, Fujisaki S, Enomoto K, Amano S, Sugitani M. Evaluation of follow-up strategies for corticosteroid therapy of idiopathic granulomatous mastitis. Surg Today. 2011 Mar; 41(3):333-7.

24 Kok KY, Telisinghe PU. Granulomatous mastitis: presentation, treatment and outcome in 43 patients. Surgeon. 2010 Aug;8(4):197-201.

25 Oran EŞ, Gürdal SÖ, Yankol Y, Öznur M, Calay Z, Tunaci M, et al. Management of idiopathic granulomatous mastitis diagnosed by core biopsy: a retrospective multicenter study. Breast J. 2013 Jul-Aug;19(4):411-8.

26 Al-Khaffaf B, Knox F, Bundred NJ. Idiopathic granulomatous mastitis: a 25-year experience. J Am Coll Surg. 2008 Feb;206(2):269-73.

27 Lai EC, Chan WC, Ma TK, Tang AP, Poon CS, Leong HT. The role of conservative treatment in idiopathic granulomatous mastitis. Breast J. 2005 Nov-Dec;11(6):454-6.

28 Fauci AS, Dale DC, Balow JE. Glucocorticosteroid therapy: mechanisms of action and clinical considerations. Ann Intern Med. 1976 Mar; 84(3):304-15.

29 Wang Z, Wang N, Liu X, Wang Q, Xu B, Liu $\mathrm{P}$, et al. Broadleaf Mahonia attenuates granulomatous lobular mastitis-associated inflammation by inhibiting CCL-5 expression in macrophages. Int J Mol Med. 2018 Jan;41(1): 340-52.

30 Tse GM, Poon CS, Ramachandram K, Ma TK, Pang LM, Law BK, et al. Granulomatous mastitis: a clinicopathological review of 26 cases. Pathology. 2004 Jun;36(3):254-7.

31 Akbulut S, Yilmaz D, Bakir S. Methotrexate in the management of idiopathic granulomatous mastitis: review of 108 published cases and report of four cases. Breast J. 2011 Nov-Dec; 17(6):661-8.

32 Kfoury H, Al Bhlal L. Granulomatous lobular mastitis: A clinicopathological study of 112 cases. Ann Saudi Med. 1997 Jan;17(1):43-6.

33 Bouton ME, Winton LM, Gandhi SG, Jayaram L, Patel PN, O’ Neill PJ, et al. Temporal resolution of idiopathic granulomatous mastitis with resumption of bromocriptine therapy for prolactinoma. Int J Surg Case Rep. 2015;10:8-11.

34 Paviour S, Musaad S, Roberts S, Taylor G, Taylor S, Shore K, et al. Corynebacterium species isolated from patients with mastitis. Clin Infect Dis. 2002 Dec;35(11):1434-40.

35 Ang LM, Brown H. Corynebacterium accolens isolated from breast abscess: possible association with granulomatous mastitis. J Clin $\mathrm{Mi}$ crobiol. 2007 May;45(5):1666-8. 